\title{
Dietary quebracho tannins are not absorbed, but increase the antioxidant capacity of liver and plasma in sheep
}

\author{
Patricia López-Andrés ${ }^{1 *}$, Giuseppe Luciano ${ }^{2}$, Valentina Vasta ${ }^{2}$, Trevor M. Gibson ${ }^{3}$, Luisa Biondi ${ }^{2}$, \\ Alessandro Priolo ${ }^{2}$ and Irene Mueller-Harvey ${ }^{4}$ \\ ${ }^{1}$ Dottorato di Ricerca in Scienze delle Produzioni Animali, University of Catania, Via Valdisavoia 5, 95123 Catania, Italy \\ ${ }^{2}$ DISPA - Sezione di Scienze delle Produzioni Animali, University of Catania, Via Valdisavoia 5, 95123 Catania, Italy \\ ${ }^{3}$ BioCentre Facility, University of Reading, Reading RG6 6AS, UK \\ ${ }^{4}$ Chemistry and Biochemistry Laboratory, Food Production and Quality Research Division, School of Agriculture, Policy and \\ Development, University of Reading, Reading RG6 6AT, UK
}

(Submitted 13 April 2012 - Final revision received 14 November 2012 - Accepted 17 November 2012 - First published online 14 January 2013)

\begin{abstract}
A total of sixteen lambs were divided into two groups and fed two different diets. Of these, eight lambs were fed a control diet (C) and eight lambs were fed the $\mathrm{C}$ diet supplemented with quebracho tannins $(\mathrm{C}+\mathrm{T})$. The objective of the present study was to assess whether dietary quebracho tannins can improve the antioxidant capacity of lamb liver and plasma and if such improvement is due to a direct transfer of phenolic compounds or their metabolites, to the animal tissues. Feed, liver and plasma samples were purified by solid-phase extraction (SPE) and analysed by liquid chromatography-MS for phenolic compounds. Profisitinidin compounds were identified in the $\mathrm{C}+\mathrm{T}$ diet. However, no phenolic compounds were found in lamb tissues. The liver and the plasma from lambs fed the $\mathrm{C}+\mathrm{T}$ diet displayed a greater antioxidant capacity than tissues from lambs fed the C diet, but only when samples were not purified with SPE. Profisetinidin tannins from quebracho seem not to be degraded or absorbed in the gastrointestinal tract. However, they induced antioxidant effects in animal tissues.
\end{abstract}

Key words: Tannins: Absorption: Antioxidant: Ruminants

Tannins are polyphenolic compounds and are widespread in the plant kingdom ${ }^{(1)}$. They can be classified into two groups: hydrolysable tannins, which contain gallic acids and their oxidation products ${ }^{(2,3)}$, and condensed tannins, which are oligomers and polymers of flavan-3-ols ${ }^{(4)}$. Tannins possess diverse biological effects because they are metal ion chelators $^{(5)}$, protein precipitating agents ${ }^{(6)}$ and antioxidants ${ }^{(7)}$.

Recent studies have shown that tannins generate antioxidant effects in vivo in different animal tissues. Luciano et $a l .^{(8)}$ have reported an improvement in the antioxidant status of muscle from lambs fed a concentrate-based diet supplemented with tannins from a quebracho (Schinopsis lorentzii) extract compared with a control tannin-free diet. In another study, Luciano et al. ${ }^{(9)}$ reported that quebracho tannins in lamb diets can improve meat colour stability by delaying myoglobin oxidation during refrigerated storage. In these studies, however, the authors did not assess whether the antioxidant effect of dietary tannins was direct, due to a transfer of phenolic compounds from feed to muscle.
It is known that many hydrolysable tannins can be degraded by micro-organisms in the rumen ${ }^{(10-15)}$. However, it is unclear to what extent microbial organisms degrade or metabolise condensed tannins. Several publications have reported that condensed tannins cannot be degraded ${ }^{(16-18)}$ by ruminal micro-organisms. In contrast, Perez-Maldonado \& Norton ${ }^{(19)}$ suggested that condensed tannins could be absorbed or degraded during metabolism in the gastrointestinal tract in sheep and goats. Furthermore, it is unclear whether these findings apply to all tannins or whether condensed tannins differ in their susceptibilities to microbial degradation.

The aim of the present study was to investigate whether quebracho tannins or their metabolites could be detected in the tissues of lambs fed a diet supplemented with quebracho extract. To achieve this objective, liver and plasma samples underwent a solid-phase extraction (SPE) step in order to purify and concentrate phenolic compounds from the samples, which were then analysed by liquid chromatography (LC)-MS. The antioxidant capacity of the samples purified with SPE was measured in order to assess whether the

Abbreviations: C, control; C + T, control + tannins; FRAP, ferric-reducing antioxidant power; LC, liquid chromatography; SPE, solid phase extraction. 
possible presence of phenolic compounds in tissues could affect their antioxidant status. Furthermore, the antioxidant status was measured in samples that had not been purified by SPE. These experiments sought to investigate whether the antioxidant effects of dietary quebracho tannins in lambs, which had been previously reported ${ }^{(8,9)}$, could be related to their transfer to animal tissues.

\section{Materials and methods}

The experimental protocol of the study, including all procedures involving animals, was approved by the University of Catania under the project Ricerca di Ateneo 2008 and by the Italian Ministry of University and Research under the project PRIN 2007 (protocol 200778K3KJ_003).

\section{Animals and diets}

A total of eighteen Comisana lambs were weaned at $45 \mathrm{~d}$ of age (mean weight 14.48 (SD 2.41) kg). Lambs were blocked in groups of two on a descending body weight basis and, within block, were assigned to one of the two dietary treatments of nine animals each $(\mathrm{C}$, control and $\mathrm{C}+\mathrm{T}$, control + tannins) and kept in individual pens for the duration of the trial (randomised complete block design). The C group received a concentrate containing the following ingredients: barley $(55.1 \%)$, alfalfa hay (30.0\%), soyabean meal $(13.0 \%)$ and vitamin and mineral premix (1.9\%). The $\mathrm{C}+\mathrm{T}$ group received the concentrate plus supplementary quebracho tannins (from S. lorentzii; Figli di Guido Lapi S.pA.). Each $1000 \mathrm{~g}$ of DM of concentrate plus tannins consisted of $95.7 \mathrm{~g}$ quebracho powder and $904.3 \mathrm{~g}$ of concentrate. The quebracho-supplemented diet was formulated to contain 6.4\% (DM basis) tannins. The lambs were adapted to the experimental diets for $7 \mathrm{~d}$ before the commencement of the experiment. After $70 \mathrm{~d}$ of experiment, the lambs were slaughtered. All lambs had access to the diets until $1 \mathrm{~h}$ before slaughtering.

\section{Sampling}

On the day before slaughtering, individual blood samples were taken from the jugular vein of each lamb after $12 \mathrm{~h}$ of fasting and collected in heparin tubes. Blood samples were centrifuged at $3000 \mathrm{~g}$ for $20 \mathrm{~min}$ at $4^{\circ} \mathrm{C}$ and stored at $-80^{\circ} \mathrm{C}$. The livers, taken after slaughtering, were immediately frozen in liquid $\mathrm{N}_{2}$, vacuum packed and stored at $-20^{\circ} \mathrm{C}$. Each type of feed was prepared in a unique batch at the beginning of the trial. Sub-samples were taken fortnightly, vacuum packed and frozen at $-20^{\circ} \mathrm{C}$. A uniform and representative sample of each diet was finally prepared for the analysis.

\section{Extraction, purification and identification of phenolic compounds}

Phenolic compounds were purified and isolated from feed and animal tissues by SPE and then identified by LC-MS analysis (see later).
Preparation of feed samples and purification of phenolic compounds by solid-phase extraction

Feeds $(2.5 \mathrm{~g})$ given to both $\mathrm{C}$ and $\mathrm{C}+\mathrm{T}$ lamb groups were placed into $50 \mathrm{ml}$ centrifuge tubes. Samples were homogenised with $15 \mathrm{ml}$ acetone-water (70-30, v/v) for $60 \mathrm{~s}$ at $4000 \mathrm{rpm}$ using a Heidolph Diax 900 tissue homogeniser (Heidolph Elektro $\mathrm{GmbH} \&$ Company KG). Samples were then sonicated for 6 min (with a break of 2 min after the first 3 min of sonication) using a Bandelin Sonoplus HD2070 sonicator (cycle: $4 \times 10 \%$, power: $0.31 \%$ ). Samples were kept in a water/ice bath during both homogenisation and sonication procedures. The sonicated homogenates were centrifuged at $3000 \boldsymbol{g}$ for $15 \mathrm{~min}$ at $4^{\circ} \mathrm{C}$ using a centrifuge (model IEC CL31R; Thermo Fisher Scientific). Then, the supernatants were filtered through Whatman 541 filter paper before SPE purification.

Phenolic compounds were isolated from feed samples on a C18 Sep-Pak Vac 6cc (500 mg) cartridge (WAT043395; WATERS SpA). The method was based on that described by PérezMagariño et $a l^{(20)}$ but was adapted as follows. Prior to use, cartridges were conditioned with $3 \mathrm{ml}$ methanol followed by $3 \mathrm{ml}$ of distilled water. The filtered supernatant $(10 \mathrm{ml})$ was acidified to $\mathrm{pH} 2.5$ with $0.5 \mathrm{M}-\mathrm{H}_{2} \mathrm{SO}_{4}$ prior to loading onto the cartridge. Phenolic compounds were eluted with $3 \mathrm{ml}$ of methanol and the final fraction was divided into two $1.5 \mathrm{ml}$ glass vials and kept in a freezer at $-30^{\circ} \mathrm{C}$.

\section{Preparation of lamb tissues and purification of phenolic compounds by solid-phase extraction}

Liver ( 5 g) was placed into a $50 \mathrm{ml}$ centrifuge tube. Preparation steps for the liver samples were carried out in the same way as for the feed samples. The SPE method was based on that described by Pérez-Magariño et al. ${ }^{(20)}$ and carried out for feed samples. For liver samples, phenolic compounds were eluted with $3 \mathrm{ml}$ of ethyl acetate. The collected fraction was evaporated to dryness under $\mathrm{N}_{2}$ and then dissolved in $3 \mathrm{ml}$ of methanol. The final fraction was also divided into two $1.5 \mathrm{ml}$ glass vials and kept at $-30^{\circ} \mathrm{C}$.

The method for the plasma samples was based on that described by Juan et $a l^{(21)}$ but was adapted as follows. A $500 \mu \mathrm{l}$ plasma aliquot was acidified with $15 \mu \mathrm{l}$ of glacial acetic acid. Phenolic compounds were isolated from plasma samples on a C18 Sep-Pak 1cc (100 mg) cartridge (WAT023590; WATERS SpA). Prior to use, the cartridges were conditioned with $3 \mathrm{ml}$ of methanol followed with $3 \mathrm{ml}$ of distilled water. The acidified plasma sample was completely loaded onto the cartridge followed by $1 \mathrm{ml}$ of distilled water. Phenolic compounds were eluted with $2 \mathrm{ml}$ of methanol. Aqueous ascorbic acid $(10 \mu \mathrm{l} ; 15 \%, \mathrm{w} / \mathrm{v})$ was added to the final eluate to prevent oxidation in plasma samples. This fraction was evaporated to dryness under $\mathrm{N}_{2}$ and then dissolved in $3 \mathrm{ml}$ of methanol. The final fraction was divided into two $1.5 \mathrm{ml}$ sub-samples and stored at $-30^{\circ} \mathrm{C}$. Samples were acidified in order to disrupt polyphenol-protein binding, as explained in Juan et al. ${ }^{(21)}$.

To confirm that the SPE method of Pérez-Magariño et al. ${ }^{(20)}$ retained phenolic compounds, we tested the method in our laboratory as follows. Three solutions of known concentrations of 
gallic acid were tested in duplicate. Standard solutions with and without SPE treatment were analysed by the Folin-Ciocalteu assay, as described later for the plasma samples. Standard solutions also underwent the SPE treatment, performed as explained earlier for plasma samples, but without the addition of ascorbic acid to the final eluate. The eluate obtained after the SPE step was evaporated to dryness under $\mathrm{N}_{2}$ and then dissolved in $1.5 \mathrm{ml}$ of methanol-distilled water $(1: 1, \mathrm{v} / \mathrm{v})$. A volume of $500 \mu \mathrm{l}$ of the final eluate was placed into a $15 \mathrm{ml}$ centrifuge tube and $500 \mu \mathrm{l}$ of methanol-distilled water $(1: 1, \mathrm{v} / \mathrm{v})$ was added. A volume of $500 \mu \mathrm{l}$ of standard solution without the SPE treatment was also placed into a $15 \mathrm{ml}$ centrifuge tube and $500 \mu \mathrm{l}$ of methanol-distilled water $(1: 1, \mathrm{v} / \mathrm{v})$ was added. In all standard solutions (with and without SPE treatment), Folin-Ciocalteu reagent was diluted to $1 \mathrm{~N}$ and $500 \mu \mathrm{l}$ were added to the tubes followed by $2.5 \mathrm{ml}$ aqueous solution of sodium carbonate $(20 \%, \mathrm{w} / \mathrm{v})$. The Folin-Ciocalteu assay was performed as described later for Folin-Ciocalteu assay in RAW samples. The results showed an $86 \cdot 35 \%$ recovery of gallic acid with $a \pm 7 \cdot 47$ of variability.

\section{Feed and tissue extracts liquid chromatography-MS analysis}

Feed and lamb tissue extracts were analysed by HPLC-MS using an ACE $52.1 \times 150 \mathrm{~mm}$ C18 column (Hichrom Limited) fitted to an Agilent 1100 liquid chromatograph with a diode array detector. A binary mobile phase system was used where solvent A was HPLC-grade water $+0 \cdot 1 \%$ formic acid and solvent B was HPLC S-grade acetonitrile $+0 \cdot 1 \%$ formic acid (Rathburn Chemicals Limited). Metabolites were eluted from the column using a simple gradient programme. Initial conditions were 95\% A and $5 \% \mathrm{~B}$ held for $1 \mathrm{~min}$, changing to $5 \% \mathrm{~A}$ and $95 \% \mathrm{~B}$ over $9 \mathrm{~min}$ and then held for $5 \mathrm{~min}$ before returning to the initial gradient conditions over $1 \mathrm{~min}$ and then held for $9 \mathrm{~min}$ to re-equilibrate the column. The pump flow rate was $0.2 \mathrm{ml} / \mathrm{min}$ and the column oven temperature was $25^{\circ} \mathrm{C}$.

For LC-MS analysis, $5 \mu \mathrm{l}$ of each sample were injected and the eluted peaks were analysed using an electrospray ionisation microTOF QII quadrupole time of flight (TOF) mass spectrometer (Bruker Daltonics) operated in the negative ion mode using a capillary voltage of $3200 \mathrm{~V}$, nebuliser gas $\left(\mathrm{N}_{2}\right)$ pressure of 1 bar, dry gas $\left(\mathrm{N}_{2}\right)$ flow of $81 / \mathrm{min}$ and a drying temperature of $180^{\circ} \mathrm{C}$. The TOF tube was set at $+8600 \mathrm{~V}$ and the detector at $2010 \mathrm{~V}$. The mass range, of 100-1700 Da, was calibrated using Agilent low concentration Tunemix (G196985000). A volume of $5 \mu \mathrm{l}$ of a standard catechin solution $(10 \mathrm{ng} / \mu \mathrm{l})$ was first injected followed by a blank with each batch of samples to check system integrity and performance. Peak areas of lipophilic compounds were normalised based on catechin areas. The method was based on that described by Wright et al. ${ }^{(22)}$ but was adapted as just mentioned.

\section{Antioxidant status of liver and plasma samples treated with or without solid-phase extraction}

Liver and plasma antioxidant status was determined by means of the ferric-reducing antioxidant power (FRAP) and
Folin-Ciocalteu assays. Both assays were applied to samples either treated (SPE samples) or not treated (RAW samples) with SPE. All samples were analysed in duplicate for FolinCiocalteu and FRAP assays.

\section{Folin-Ciocalteu assay on RAW samples}

For the preparation of RAW-liver for the Folin-Ciocalteu assay, $2 \mathrm{~g}$ of the liver was placed into a $50 \mathrm{ml}$ centrifuge tube and homogenised with $10 \mathrm{ml}$ of distilled water. Homogenisation, sonication, centrifugation and filtration steps were performed as described earlier for SPE liver. A 1:4 dilution of the extract $(3 \mathrm{ml}$ of distilled water added to $1 \mathrm{ml}$ of liver extract) was chosen. The assay was performed as described by Luciano et al. ${ }^{(8)}$. Briefly, $100 \mu \mathrm{l}$ of the diluted RAW-liver extract were transferred into $15 \mathrm{ml}$ centrifuge tubes and $900 \mu \mathrm{l}$ of distilled water was added. The FolinCiocalteu reagent was diluted to $1 \mathrm{~N}$ and $500 \mu$ l were added to the tubes followed by $2.5 \mathrm{ml}$ aqueous solution of sodium carbonate $(20 \%, \mathrm{w} / \mathrm{v})$. The mixture was vortex mixed for $30 \mathrm{~s}$ and incubated for $40 \mathrm{~min}$ in the dark at room temperature. The samples were centrifuged at $2700 \mathrm{~g}$ for $10 \mathrm{~min}$ at $4{ }^{\circ} \mathrm{C}$ in order to remove any sodium carbonate precipitates. A double-beam spectrophotometer (model UV-1601; Shimadzu Corporation) was used to measure the absorbance of the samples. The wavelength used was $725 \mathrm{~nm}$ and a tube containing all the reagents except the tissue extract was used as a blank. Aqueous solutions of gallic acid were used for the calibration curve. The concentration range for the calibration curve covered 0 to $80 \mu \mathrm{g} / \mu \mathrm{l}$ of gallic acid. The results were expressed as $\mathrm{mg}$ of gallic acid equivalents/g of liver. For RAW-plasma samples, $100 \mu \mathrm{l}$ of plasma diluted in the ratio 1:10 with distilled water were taken in $15 \mathrm{ml}$ centrifuge tubes and $900 \mu \mathrm{l}$ of distilled water were added. The FolinCiocalteu assay was carried out as described for RAW-liver samples. The results were expressed as $\mathrm{mg}$ of gallic acid equivalents $/ \mathrm{ml}$ of plasma.

\section{Folin-Ciocalteu assay of solid-phase extraction-treated samples}

The liver and plasma samples treated with SPE were subjected to the Folin-Ciocalteu assay as follows. The content of one of the two $1.5 \mathrm{ml}$ glass vials obtained after the SPE step was evaporated to dryness under $\mathrm{N}_{2}$ and then dissolved in $1.5 \mathrm{ml}$ of methanol-distilled water $(1: 1, \mathrm{v} / \mathrm{v})$. In the case of SPE-liver samples, $500 \mu \mathrm{l}$ of this extract were transferred into a $15 \mathrm{ml}$ centrifuge tube and $500 \mu \mathrm{l}$ of methanol-distilled water $(1: 1, \mathrm{v} / \mathrm{v})$ were added. The Folin-Ciocalteu assay was performed as described earlier for RAW-liver. Solutions of gallic acid in 1:1 ( $\mathrm{v} / \mathrm{v})$ methanol-distilled water were used to calibrate the assay.

For measuring the total phenolic content and the antioxidant status in plasma, SPE-plasma samples were obtained as described earlier, with the only difference that ascorbic acid was not added to the final sample; in fact, Georgé et al. ${ }^{(23)}$ showed that ascorbic acid interferes in the Folin-Ciocalteu assay. The final SPE-plasma extracts were evaporated to dryness under $\mathrm{N}_{2}$ and then dissolved in $3 \mathrm{ml}$ of methanol-distilled 
water $(1: 1, \mathrm{v} / \mathrm{v})$; a volume of $500 \mu \mathrm{l}$ of this sample was placed into a $15 \mathrm{ml}$ centrifuge tube and $500 \mu \mathrm{l}$ of methanol-distilled water $(1: 1, \mathrm{v} / \mathrm{v})$ were added. The Folin-Ciocalteu assay was performed as described for RAW-liver. The results were expressed as $\mathrm{mg}$ of gallic acid equivalents/ $\mathrm{ml}$ of plasma.

\section{Ferric-reducing antioxidant power assay of RAW samples}

The method described by Luciano et $a l .{ }^{(8)}$ was followed to measure the FRAP. The FRAP reagent was prepared by mixing ten volumes of acetate buffer ( $300 \mathrm{~mm}, \mathrm{pH} 3.6)$ with one volume of a solution of 2,4,6-tripyridyl-S-triazine (TPTZ; $10 \mathrm{~mm}$ in $40 \mathrm{~mm}-\mathrm{HCl}$ ) and with one volume of $20 \mathrm{~mm}$-aqueous ferric chloride. A blank reading at $593 \mathrm{~nm}$ was taken immediately after mixing $400 \mu \mathrm{l}$ of distilled water with $3 \mathrm{ml}$ of FRAP reagent. For RAW-liver samples, $0.5 \mathrm{~g}$ of liver were placed into a $50 \mathrm{ml}$ centrifuge tube and $10 \mathrm{ml}$ of distilled water were added. Homogenisation, sonication, centrifugation and filtration steps were performed as described earlier for SPE-liver samples. Then, in a glass test tube, $300 \mu \mathrm{l}$ of distilled water were mixed with $100 \mu \mathrm{l}$ of liver extract and $3 \mathrm{ml}$ of warm FRAP reagent $\left(37^{\circ} \mathrm{C}\right)$ were added. The contents of the tube were mixed and incubated in a water bath set at $37^{\circ} \mathrm{C}$ for $4 \mathrm{~min}$, after which the absorbance was recorded at $593 \mathrm{~nm}$. The change in absorbance $\left(\Delta A_{593 \mathrm{~nm}}\right)$ between the final reading and the blank reading was related to that obtained with solutions of $\mathrm{Fe}^{2+}$ of known concentrations (aqueous $\mathrm{FeSO}_{4} \cdot 7 \mathrm{H}_{2} \mathrm{O}$ ranging from 0 to $1000 \mu \mathrm{m}$ ). Results of the FRAP assay were therefore expressed as $\mu \mathrm{mol}$ of $\mathrm{Fe}^{2+}$ equivalents/g of liver. For RAW-plasma samples, $74 \mu \mathrm{l}$ of plasma were added in a glass test tube containing $220 \mu \mathrm{l}$ of distilled water and $2.2 \mathrm{ml}$ of FRAP reagent (the final dilution of the sample in the mixture was always 1:34). Tubes were mixed and incubated for $4 \mathrm{~min}$ in a water bath at $37^{\circ} \mathrm{C}$. The absorbance was immediately recorded at $593 \mathrm{~nm}$. Results of the FRAP assay were therefore expressed as $\mu \mathrm{mol}$ of $\mathrm{Fe}^{2+}$ equivalents/ml of plasma.

\section{Ferric-reducing antioxidant power assay in solid-phase extraction samples}

The same method described earlier was applied to the SPE samples. Since SPE samples were prepared in a methanol -distilled water solution, the same solution was used instead of distilled water in the assay, as well as for preparing standard FeSO $4.7 \mathrm{H}_{2} \mathrm{O}$ solutions. The assay was performed by adding in a glass test tube $200 \mu \mathrm{l}$ of the SPE-liver samples or SPE-plasma samples (without ascorbic acid) to $200 \mu$ l of methanol-distilled water and $3 \mathrm{ml}$ of FRAP reagent. Incubation time, absorbance measurement and calculations were performed as described earlier.

\section{Statistical analyses}

The data for the lipophilic compounds were analysed by oneway ANOVA to test the effect of the dietary treatment ( $\mathrm{C} v$. $\mathrm{C}+\mathrm{T}$ ) and experimental error.

To test the effects of the SPE method used and of the dietary supplementation with tannin extract, the data of Folin-Ciocalteu and FRAP assays performed on the liver and plasma were analysed as repeated measures using the MIXED procedure of the statistical software SAS (version 9). The fixed effects tested in the model were the dietary treatment (Diet; $\mathrm{C}$ or $\mathrm{C}+\mathrm{T}$ ), the purification or not with SPE (RAW samples or SPE samples) and their interaction (Diet $\times$ SPE). The individual lamb was included in the model as a random effect nested with the Diet. The covariance structure used was the variance components. Multiple comparisons of the least squares means, presented in Table 3, were performed using the PDIFF option of SAS and the Tukey's adjustment for multiple comparisons was adopted.

In all the statistical analyses performed, significance was declared for $P \leq 0.05$; when $0.05<P \leq 0.1$, the means were considered as different in tendency.

\section{Results}

\section{Analysis of feed samples by liquid chromatography-MS}

Representative chromatograms of quebracho-enriched and control diets are shown in Fig. S1 of the supplementary material (available online). The quebracho chromatogram differed from the control by the presence of one peak at $12 \cdot 1 \mathrm{~min}$. The extracted ion chromatogram revealed that this peak contained several different masses (see Fig. S2 of the supplementary material, available online) with $m / z(\mathrm{M}-\mathrm{H})^{-}$of $561 \cdot 150,833 \cdot 223$ and $1105 \cdot 293$. These compounds were identified as a combination of one or more fisetinidol units plus one catechin unit (see Fig. S3 of the supplementary material (available online); Table 1). Another single peak was observed at 12.8 min with an $\mathrm{m} / z(\mathrm{M}-\mathrm{H})^{-}$of 285.046 and was identified as fisetin (see Fig. S4 of the supplementary material (available online); Table 1). LC-MS analysis of the control diet revealed the absence of the compounds identified in the quebrachoenriched diet.

\section{Analysis of animal tissues by liquid chromatography-MS}

Plasma and the liver extracts obtained after the SPE step were analysed for quebracho profisetinidins and other phenolic compounds or possible metabolites arising from their degradation. Under the LC-MS conditions used in the present

Table 1. Main phenolic compounds identified in the quebracho-enriched diet by liquid chromatography-MS

\begin{tabular}{lccll}
\hline Compound & $m / z(\mathrm{M}-\mathrm{H})^{-}$Observed & $m / z(\mathrm{M}-\mathrm{H})^{-}$Calculated & Formula & Assignments \\
\hline 1 & 285.046 & 285.0401 & $\mathrm{C}_{15} \mathrm{H}_{10} \mathrm{O}_{6}$ & Fisetin \\
2 & 561.150 & 561.1394 & $\mathrm{C}_{30} \mathrm{H}_{26} \mathrm{O}_{11}$ & Dimer consisting of one fisetinidol unit plus one catechin unit \\
3 & 833.223 & 833.2075 & $\mathrm{C}_{45} \mathrm{H}_{38} \mathrm{O}_{16}$ & Trimer consisting of two fisetinidol units plus one catechin unit \\
4 & 1105.293 & 1105.2756 & $\mathrm{C}_{60} \mathrm{H}_{50} \mathrm{O}_{21}$ & Tetramer consisting of three fisetinidol units plus one catechin unit \\
\hline
\end{tabular}

* See Fig. S3 of the supplementary material (available online) for chemical structures. 
study, phenolic compounds were expected to elute between 5 and $12 \mathrm{~min}$. However, no signals from any of these compounds could be detected in the liver (see Fig. S5 of the supplementary material, available online) or plasma (see Fig. S6 of the supplementary material, available online) samples from lambs fed the $\mathrm{C}+\mathrm{T}$ diet. Liver chromatograms from lambs fed the $\mathrm{C}$ or $\mathrm{C}+\mathrm{T}$ diet were exactly the same. In plasma chromatograms, no differences could be found between the lambs fed with the different diets. In plasma chromatograms, the peak at $2.5 \mathrm{~min}$ is ascorbic acid, which had been added during the SPE step. Although in plasma chromatograms (Fig. S6, available online) some peaks were observed between 5 and $12 \mathrm{~min}$, these peaks belonged to nitrogen-containing compounds rather than phenolic compounds. For this reason, these compounds were not analysed further. The peaks observed between 12 and $25 \mathrm{~min}$ in the chromatograms from the plasma and the liver samples are due to lipophilic compounds (Table 2); the plasma of the $\mathrm{C}+\mathrm{T}$ lambs presented greater $(P \leq 0.008)$ amounts of $\mathrm{C}_{18} \mathrm{H}_{30} \mathrm{O}_{2}, \mathrm{C}_{18} \mathrm{H}_{32} \mathrm{O}_{2}$, and $\mathrm{C}_{20} \mathrm{H}_{30} \mathrm{O}_{2}$ and the compound $\mathrm{C}_{18} \mathrm{H}_{34} \mathrm{O}_{2}$ showed a tendency $(P=0.09)$ compared with the $\mathrm{C}$ animals. No significant differences $(P>0.05)$ were found in the amounts of the lipophilic compounds detected in the liver samples of the lambs from the two groups.

\section{Folin-Ciocalteu assay in lamb tissues}

As shown in Table 3, the SPE purification procedure $(P<0 \cdot 0001)$ had an effect on the results from the Folin-Ciocalteu assay, which were obtained from the liver samples. Lower values were measured in the SPE samples compared with the RAW samples, regardless of the dietary treatment. The dietary treatment tended to affect the values of the Folin-Ciocalteu assay of the liver samples $(P=0.062)$; however, tendency was detectable in the Diet $\times$ SPE interaction $(P=0 \cdot 061)$. The multiple comparisons test showed that the RAW samples from animals fed the $\mathrm{C}+\mathrm{T}$ diet tended to have higher values of the Folin-Ciocalteu assay compared with those from the lambs fed the C diet $(+9.93 \%$, $P=0.073$; Table 3). Conversely, no difference in the FolinCiocalteu values was observed between the $\mathrm{C}$ and $\mathrm{C}+\mathrm{T}$ groups when the liver samples underwent the SPE purification step (SPE samples). A similar trend was observed more clearly when the Folin-Ciocalteu assay was performed on the plasma samples, with values of the SPE samples being significantly lower compared with those measured in the RAW samples $(P<0.0001)$. A significant effect of Diet was found, as well as a significant Diet $\times$ SPE interaction $(P=0.005$ and 0.008, respectively; Table 3). Multiple comparisons between means showed that RAW-plasma samples from lambs fed the $\mathrm{C}+\mathrm{T}$ diet had higher Folin-Ciocalteu values as compared with samples from lambs fed the $\mathrm{C}$ diet $(+5.86 \%, P=0.003$; Table 3$)$. However, no difference between the $\mathrm{C}$ - and the $\mathrm{C}+\mathrm{T}$-fed animals was found when the plasma was subjected to the SPE treatment.

\section{Ferric-reducing antioxidant power assay in lamb tissues}

As shown in Table 3, the SPE purification procedure strongly reduced the values of the FRAP assay in the liver samples, regardless of the dietary treatment $(P<0 \cdot 0001)$. Diet significantly affected the FRAP values of the liver $(P=0.050)$; however, a significant Diet $\times$ SPE interaction $(P=0.050)$ showed how the Diet effect was dependent on the purification of the samples by the SPE. Indeed, multiple comparisons showed that FRAP values were higher in RAW-liver samples from lambs fed the $\mathrm{C}+\mathrm{T}$ diet compared with the $\mathrm{C}$ diet ( $+13.28 \%, P=0.050$; Table 3); conversely, no difference between the $\mathrm{C}+\mathrm{T}$ and $\mathrm{C}$ diets were observed in the SPE-liver samples. Similarly, the SPE purification overall reduced the FRAP values measured in plasma $(P<0.0001)$, an effect of Diet was found $(P=0 \cdot 001)$, as well as a Diet $\times$ SPE interaction $(P=0.0008)$. As observed in the liver samples, the $\mathrm{C}+\mathrm{T}$ diet resulted in higher FRAP values in the RAW-plasma samples compared with the $\mathrm{C}$ diet $(+32.57 \%, P=0.0002$; Table 3$)$. However, there was no difference in FRAP values between the $\mathrm{C}$ and $\mathrm{C}+\mathrm{T}$ diets in the SPE-plasma samples.

\section{Discussion}

To the best of our knowledge, the present study is the first aiming to determine the metabolic fate of quebracho tannins after being ingested by ruminants. So far, the use of quebracho in ruminant diets has been investigated with respect to their toxicity $^{(24)}$, their anthelmintic effect ${ }^{(25)}$, N utilisation ${ }^{(26)}$, their role in lipid metabolism ${ }^{(27)}$ and meat colour ${ }^{(8,9)}$. Vasta et $a l{ }^{(28)}$ reported that supplementing lambs with quebracho tannins increased the expression in the longissimus dorsi

Table 2. Lipophilic compounds* found in the liver and plasma of lambs fed concentrate $(C)$ or $C$ plus quebracho tannins $(C+T)$

\begin{tabular}{|c|c|c|c|c|c|c|c|c|c|c|}
\hline \multirow{3}{*}{$\begin{array}{l}m / z(\mathrm{M}-\mathrm{H})^{-} \\
\text {observed }\end{array}$} & \multirow{3}{*}{$\begin{array}{l}m / z(\mathrm{M}-\mathrm{H})^{-} \\
\text {calculated }\end{array}$} & \multirow[b]{3}{*}{ Formula } & \multicolumn{4}{|c|}{ Liver } & \multicolumn{4}{|c|}{ Plasma } \\
\hline & & & \multicolumn{4}{|c|}{ Diet } & \multicolumn{4}{|c|}{ Diet } \\
\hline & & & C & $\mathrm{C}+\mathrm{T}$ & $P$ & SEM & C & $\mathrm{C}+\mathrm{T}$ & $P$ & SEM \\
\hline $255 \cdot 235$ & $255 \cdot 232$ & $\mathrm{C}_{16} \mathrm{H}_{32} \mathrm{O}_{2}$ & $4 \cdot 257$ & $5 \cdot 331$ & 0.402 & 0.6160 & $5 \cdot 025$ & 5.533 & 0.128 & 0.165 \\
\hline $265 \cdot 151$ & $266 \cdot 151$ & $\mathrm{C}_{15} \mathrm{H}_{22} \mathrm{O}_{4}$ & $7 \cdot 179$ & $7 \cdot 353$ & 0.090 & 0.0514 & $6 \cdot 381$ & 6.519 & 0.104 & 0.0421 \\
\hline $277 \cdot 221$ & $277 \cdot 217$ & $\mathrm{C}_{18} \mathrm{H}_{30} \mathrm{O}_{2}$ & $6 \cdot 901$ & $7 \cdot 044$ & 0.256 & 0.0612 & 4.587 & $5 \cdot 142$ & 0.001 & 0.0961 \\
\hline $279 \cdot 236$ & $279 \cdot 232$ & $\mathrm{C}_{18} \mathrm{H}_{32} \mathrm{O}_{2}$ & $7 \cdot 197$ & $7 \cdot 243$ & 0.159 & 0.0161 & 4.819 & $5 \cdot 392$ & 0.001 & 0.0973 \\
\hline $281 \cdot 251$ & $281 \cdot 248$ & $\mathrm{C}_{18} \mathrm{H}_{34} \mathrm{O}_{2}$ & $5 \cdot 300$ & $6 \cdot 870$ & 0.218 & 0.6220 & $5 \cdot 395$ & $5 \cdot 812$ & 0.090 & 0.1230 \\
\hline $299 \cdot 263$ & $299 \cdot 257$ & $\mathrm{C}_{18} \mathrm{H}_{36} \mathrm{O}_{3}$ & $6 \cdot 203$ & $6 \cdot 255$ & 0.575 & 0.0443 & - & - & - & - \\
\hline $301 \cdot 221$ & $301 \cdot 217$ & $\mathrm{C}_{20} \mathrm{H}_{30} \mathrm{O}_{2}$ & $7 \cdot 117$ & $7 \cdot 116$ & 0.967 & 0.0175 & 5.555 & 5.675 & 0.008 & 0.0241 \\
\hline
\end{tabular}

*Data expressed as log of peak area. 
Table 3. Folin-Ciocalteu and ferric-reducing antioxidant power (FRAP) values measured on RAW samples and solid phase extraction (SPE) samples

(Least square mean values with their pooled standard errors)

\begin{tabular}{|c|c|c|c|c|c|c|c|c|}
\hline & \multicolumn{2}{|c|}{ Raw samples } & \multicolumn{2}{|c|}{ SPE samples } & \multirow[b]{2}{*}{ SE } & \multicolumn{3}{|c|}{$P^{*}$} \\
\hline & C & $\mathrm{C}+\mathrm{T}$ & C & $C+T$ & & Diet & SPE & Diet $\times$ SPE \\
\hline Number of animals & 8 & 8 & 8 & 8 & & & & \\
\hline \multicolumn{9}{|l|}{ Liver } \\
\hline Folin-Ciocalteu assay $†$ & $4 \cdot 054^{a}$ & $4.501^{a}$ & $0.010^{\mathrm{b}}$ & $0.009^{b}$ & 0.110 & 0.062 & $<0.0001$ & 0.061 \\
\hline FRAP assay $\ddagger$ & $17 \cdot 971^{b}$ & $20 \cdot 725^{a}$ & $0.071^{\mathrm{C}}$ & $0.074^{c}$ & 0.643 & 0.050 & $<0.0001$ & 0.050 \\
\hline \multicolumn{9}{|l|}{ Plasma } \\
\hline Folin-Ciocalteu assay† & $1.927^{b}$ & $2 \cdot 047^{\mathrm{a}}$ & $0.016^{c}$ & $0.021^{\mathrm{c}}$ & 0.019 & 0.005 & $<0.0001$ & 0.008 \\
\hline FRAP assay $\ddagger$ & $0.387^{b}$ & $0.574^{\mathrm{a}}$ & $0 \cdot 162^{c}$ & $0 \cdot 160^{c}$ & 0.022 & 0.001 & $<0.0001$ & 0.0008 \\
\hline
\end{tabular}

$\mathrm{C}$, concentrate; $\mathrm{C}+\mathrm{T}, \mathrm{C}$ plus quebracho tannins.

${ }^{a, b, c}$ Mean values within a row with unlike superscript letters were significantly different between least squares means $(P<0.05)$ tested using the Tukey's adjustment for multiple comparisons.

${ }^{*} P$ values of the test of the fixed effects performed with the mixed procedure statistical analysis. The fixed effects tested were dietary treatment (Diet; $C$ or $\left.C+T\right)$, SPE treatment (SPE; RAW samples or SPE samples) and their interaction (Diet $\times$ SPE).

† Expressed as $\mathrm{mg}$ of gallic acid equivalents $(\mathrm{GAE}) / \mathrm{g}$ of liver, or as $\mathrm{mg}$ of $\mathrm{GAE} / \mathrm{ml}$ of plasma.

$\ddagger$ Expressed as $\mu \mathrm{mol}$ of $\mathrm{Fe}^{2+}$ equivalents $/ \mathrm{g}$ of liver, or as $\mu \mathrm{mol}$ of $\mathrm{Fe}^{2+}$ equivalents $/ \mathrm{ml}$ of plasma.

muscle of the $\Delta 9$ desaturase enzyme compared with lambs fed the same diet but without a quebracho supplement. Luciano et $a l .^{(8,9)}$ reported that supplementary quebracho increased muscle antioxidant status and reduced the discolouration in lamb meat stored for up to $11 \mathrm{~d}$ in a modified atmosphere ${ }^{(9)}$ or up to $7 \mathrm{~d}$ in aerobic conditions ${ }^{(8)}$. These effects observed in muscles imply that dietary quebracho tannins can affect the post-digestive metabolism. Two possible mechanisms could explain these observations: (i) ingested quebracho tannins (or their metabolites) might be degraded and absorbed from the ruminant digestive tract before being transferred to tissues or (ii) dietary quebracho tannins (and their metabolites) are not absorbed in the digestive tract but act instead as antioxidants in the gastrointestinal tract ${ }^{(29)}$. It is wellknown that tannins form complexes with proteins and interfere with ruminal digestion in general. Protein complexation affects but does not eliminate the antioxidant activities of tannins ${ }^{(30,31)}$. Therefore, it is possible that tannins may indirectly affect muscle biochemistry via some other components. In the light of these speculations, the present study investigated whether or not dietary quebracho tannins or their metabolites were present in lamb plasma and liver.

The main types of tannins found in the quebracho-enriched diet were profisetinidins (Table 1) and have been described previously in quebracho extracts ${ }^{(32,33)}$. It should be noted that, in contrast to most other condensed tannins, profisetinidins do not contain 5-OH groups in close proximity to the interflavanol bond. The absence of this $5-\mathrm{OH}$ group increases the stability of the interflavanol linkages in condensed tannins ${ }^{(34)}$, and therefore quebracho tannins are particularly difficult to degrade.

The bioavailability of phenolic compounds in ruminants has been only marginally investigated. Gladine et $a l^{(35)}$ found monomeric phenol compounds in plasma when the sheep had received polyphenol-rich plant (i.e. grape or rosemary) extracts by ruminal infusion. Moñino et al. ${ }^{(36)}$ reported that the muscle of lambs receiving the milk of ewes fed with a rosemary-enriched concentrate contained several of the phenols that were present in the diet of the ewe. These studies suggested that only some phenolic compounds are bioavailable. Clearly, the chemical structures of tannins and phenolic acids studied by Gladine et $a l^{(35)}$ and Moñino et $a{ }^{(36)}$ differ from the profisitenidins investigated in the present study (see Fig. S3 of the supplementary material, available online)

The present study demonstrated that, with the analytical procedures adopted, no phenolic compounds could be detected in lamb tissues, which leads us to consider that the profisetinidin tannins from quebracho might not be degraded or absorbed in the gastrointestinal tract. This agrees with Makkar et al. ${ }^{(16)}$ who reported that quebracho tannins, as measured by the butanol- $\mathrm{HCl}-\mathrm{Fe}^{3+}$ reagent ${ }^{(37)}$, are not degraded by ruminal micro-organisms in an in vitro study. Therefore, it is likely that these types of tannins are directly eliminated through the faeces. Nevertheless, other authors reported that ruminal microflora were able to degrade quebracho tannins into smaller phenolic compounds ${ }^{(38)}$.

We found that the RAW-liver and RAW-plasma samples of the $\mathrm{C}+\mathrm{T}$ lambs displayed higher FRAP and Folin-Ciocalteu values than the samples from the control lambs. These results agree with those reported by Luciano et al. ${ }^{(8)}$ who showed that tannins from quebracho increased the antioxidant status in lamb muscle measured as Folin-Ciocalteu or FRAP values. However, the Folin-Ciocalteu and the FRAP reagents are not specific to phenolic compounds and react to a wide spectrum of reducing compounds ${ }^{(22)}$, while the SPE method used is highly selective for the isolation and concentration of phenolic compounds ${ }^{(20)}$. The much lower FRAP and FolinCiocalteu values found here in the SPE samples compared with RAW samples are likely to be due to the removal of antioxidants other than phenolic compounds by the SPE treatment. Moreover, when the liver and the plasma extracts were passed through SPE cartridges, no difference in the Folin-Ciocalteu and FRAP tests was found between lambs fed with the control diet or with the quebracho-enriched diet. In the light of this, the higher antioxidant capacity of RAW-liver and RAW-plasma from lambs fed the $\mathrm{C}+\mathrm{T}$ diet 
suggests that dietary tannins are able to positively affect the antioxidant status of the animal tissues. However, the lack of difference between the $\mathrm{C}$ and $\mathrm{C}+\mathrm{T}$ treatments in the antioxidant capacity measured after SPE treatment of the liver and the plasma samples, together with the absence of phenolic compounds in these tissues, leads us to believe that the antioxidant effects of dietary quebracho tannins were not directly related to their absorption and deposition in the tissues. Rather, the improved antioxidant capacity of the liver and the plasma from lambs fed quebracho appears to result from unknown and indirect antioxidant mechanisms ${ }^{(39)}$. These effects could be mediated, for example, by a direct antioxidant activity of the tannins in the gastrointestinal tract, such as a removal or chelation of pro-oxidant compounds and a reduction of lipid peroxidation, which would result in an overall improvement of the animal's antioxidant status ${ }^{(29,40)}$. Furthermore, it is known that dietary condensed tannins strongly modify lipid metabolism in ruminants ${ }^{(27)}$ and also interfere with gene $^{(41)}$ and protein expression ${ }^{(28)}$. In particular, Sgorlon et $a l .{ }^{(42)}$ found that supplementing sheep with grape skin extract, which is rich in polyphenols and condensed tannins, increased the expression in plasma of the superoxide dismutase enzyme, which is involved in the endogenous antioxidant defence system. Interestingly, Larrosa et al. ${ }^{(43)}$ recently reported that hydrolysable tannins also resulted in indirect antioxidant mechanisms in monogastric animals.

The lipophilic compounds detected in the liver and the plasma are likely to be fatty acids and, in particular, the formulae $\mathrm{C}_{18} \mathrm{H}_{30} \mathrm{O}_{2}, \mathrm{C}_{18} \mathrm{H}_{32} \mathrm{O}_{2}$ and $\mathrm{C}_{20} \mathrm{H}_{30} \mathrm{O}_{2}$ could correspond to $\mathrm{C}_{18}$ and $\mathrm{C}_{20}$ PUFA and $\mathrm{C}_{18} \mathrm{H}_{34} \mathrm{O}_{2}$ could correspond to a MUFA. The plasma of the $\mathrm{C}+\mathrm{T}$ lambs contained more of these compounds than the plasma of $\mathrm{C}$ lambs (Table 2). It is known that feeding tannins increases PUFA accumulation in the tissues ${ }^{(27)}$; this is due to a reduced biohydrogenation of PUFA in the rumen, as tannins depress the relative abundance of some bacterial strains responsible for the biohydrogenation ${ }^{(25)}$.

In conclusion, with the analytical procedures adopted in the present study, no tannins or other phenolic compounds could be detected in the liver or the plasma samples when lambs were fed a quebracho-supplemented diet. This is in contrast with studies in which plant extracts rich in other types of polyphenols and tannins were given to lambs. The present results are likely to be due both to the very low amount of fisetin (a low-molecular-weight phenol) and to the structural stability of profisetinidins in quebracho. Although no phenolic compounds were detected in the liver and plasma of quebrachofed lambs, these tissues showed a greater antioxidant capacity compared with the liver and plasma of unsupplemented lambs. Therefore, it can be concluded that supplementing quebracho tannins improves the antioxidant capacity of tissues via an indirect effect, possibly by enhancing the tissue endogenous antioxidant system or by participating in the regeneration of other antioxidant compounds.

\section{Supplementary material}

To view supplementary material for this article, please visit http://dx.doi.org/10.1017/S0007114512005703

\section{Acknowledgements}

This research was funded by the University of Catania, Progetto di Ricerca di Ateneo, 2008 (main investigator L. B.) and by the Italian Ministry of Research, PRIN 2007, protocol 200778K3KJ_03, entitled Effects of Tannins on Sheep and Goat Meat Quality (main investigator, A. P.). P. L.-A. planned and performed all the analyses and wrote the manuscript. G. L. was responsible for the organisation of the in vivo experiment, assisted in the analyses of the antioxidant status parameters and in the analysis and discussion of the results. T. M. G. provided assistance for LC-MS analyses. I. M.-H. supervised all the activities at the University of Reading related to the optimisation of the analyses of phenolic compounds and contributed to the interpretation of the related results. V. V. supervised the optimisation of the SPE purification of phenolic compounds. The experiment was designed by A. P. and L. B. The authors gratefully acknowledge Dr Corrado Dimauro (Dipartimento di Scienze Zootecniche, University of Sassary, Italy) for assistance in data analyses. The authors declare no conflict of interest.

\section{References}

1. Yoshida T, Hatano T \& Ito H (2000) Chemistry and function of vegetable polyphenols with high molecular weights. BioFactors 13, 121-125.

2. Mueller-Harvey I (2001) Analysis of hydrolysable tannins. Anim Feed Sci Technol 91, 3-20.

3. Hartzfeld PW, Forkner R, Hunter MD, et al. (2002) Determination of hydrolyzable tannins (gallotannins and ellagitannins) after reaction with potassium iodate. J Agric Food Chem 50, 1785-1790.

4. Porter LJ (1992) Structure and chemical properties of the condensed tannins. In Plant Polyphenols, Synthesis, Properties and Significance, pp. 245-258 [RW Hemingway and PE Laks, editors]. New York: Plenum.

5. McDonald M, Mila I \& Scalbert A (1996) Precipitation of metal ions by plant polyphenols: optimal conditions and origin of precipitation. J Agric Food Chem 44, 599-606.

6. Santos-Buelga C \& Scalbert A (2000) Proanthocyanidins and tannin-like compounds - nature, occurrence, dietary intake and effects on nutrition and health. J Sci Food Agric 80, $1094-1117$.

7. Hagerman AE, Riedl KM, Jones GA, et al. (1998) High molecular weight plant polyphenolics (tannins) as biological antioxidants. J Agric Food Chem 46, 1887-1892.

8. Luciano G, Vasta V, Monahan FJ, et al. (2011) Antioxidant status, colour stability and myoglobin resistance to oxidation of longissimus dorsi muscle from lambs fed a tannin-containing diet. Food Chem 124, 1036-1042.

9. Luciano G, Monahan FJ, Vasta V, et al. (2009) Dietary tannins improve lamb meat color stability. Meat Sci 81, 120-125.

10. McSweeny CS, Palmer B, McNeill DM, et al. (2001) Microbial interactions with tannins: nutritional consequences for ruminants. Anim Feed Sci Technol 91, 83-93.

11. Brooker JD, O'Donovan LA, Skene I, et al. (1994) Streptococcus caprinus sp.nov. a tannin-resistant ruminal bacterium from feral goats. Lett Appl Microbiol 18, 313-318.

12. Nelson KE, Pell AN, Schofield P, et al. (1995) Isolation and characterization of an anaerobic ruminal bacterium capable of degrading hydrolyzable tannins. Appl Environ Microb 61, 3293-3298. 
13. Skene IK \& Brooker JD (1995) Characterization of tannin acylhydrolase activity in the ruminal bacterium Selenomonas ruminantium. Anaerobe 1, 321-327.

14. Sly LI, Cahill MM, Osawa R, et al. (1997) The tannin-degrading species Streptococcus gallolyticus and Streptococcus caprinus are subjective synonymus. Int J Syst Bacteriol $\mathbf{4 7}$, 893-894.

15. Goel G, Puniya AK, Aguilar CN, et al. (2005) Interaction of gut microflora with tannins in feeds. Naturwissenschaften 92, 497-503.

16. Makkar HPS, Becker K, Abel H, et al. (1995) Degradation of condensed tannins by rumen microbes exposed to quebracho tannins (QT) in rumen simulation technique (RUSITEC) and effects of QT on fermentative processes in the RUSITEC. J Sci Food Agric 69, 495-500.

17. Getachew G, Pittroff W, Putnam DH, et al. (2008) The influence of addition of gallic acid, tannic acid, or quebracho tannins to alfalfa hay on in vitro rumen fermentation and microbial protein synthesis. Anim Feed Sci Technol 140, 444-461.

18. Bhat TK, Makkar HPS \& Singh B (1996) Isolation of a tanninprotein complex-degrading fungus from faeces of hill cattle. Lett Appl Microbiol 22, 257-258.

19. Perez-Maldonado RA \& Norton BW (1996) Digestion of ${ }^{14} \mathrm{C}$-labelled condensed tannins from Desmodium intortum in sheep and goats. BrJ Nutr 76, 501-513.

20. Pérez-Magariño S, Ortega-Heras M \& Cano-Mozo E (2008) Optimization of a solid-phase extraction method using copolymer sorbents for isolation of phenolic compounds in red wines and quantification by HPLC. J Agric Food Chem 56, 11560-11570.

21. Juan ME, Maijó M \& Planas JM (2010) Quantification of transresveratrol and its metabolites in rat plasma and tissues by HPLC. J Pharmaceut Biomed 51, 391-398.

22. Wright B, Gibson T, Spencer J, et al. (2010) Platelet-mediated metabolism of the common dietary flavonoid, quercetin. PLoS One 5, e9673.

23. Georgé S, Brat P, Alter P, et al. (2005) Rapid determination of polyphenols and vitamin C in plant-derived products. J Agric Food Chem 53, 1370-1373.

24. Hervás G, Pérez V, Giráldez FJ, et al. (2003) Intoxication of sheep with quebracho tannin extract. J Comp Path 129, $44-54$.

25. Athanasiadou S, Kyriazakis I, Jackson F, et al. (2001) Direct anthelmintic effects of condensed tannins towards different gastrointestinal nematodes of sheep: in vitro and in vivo studies. Vet Parasitol 99, 205-219.

26. Waghorn GC, Shelton ID, McNabb WC, et al. (1994) Effects of condensed tannins in Lotus pedunculatus on its nutritive value for sheep. 2. Nitrogenous aspects. J Agric Sci 123, 109-119.

27. Vasta V, Mele M, Scerra M, et al. (2009) Metabolic fate of fatty acids involved in ruminal biohydrogentaion in sheep fed concentrate or herbage with or without tannins. J Anim Sci 87, 2674-2684.

28. Vasta V, Priolo A, Scerra M, et al. (2009) $\Delta 9$ desaturase protein expression and fatty acid composition of longissimus dorsi muscle in lambs fed green herbage or concentrate with or without added tannins. Meat Sci 82, 357-364.

29. Kerem Z, Chertrit D, Shoseyov O, et al. (2006) Protection of lipids from oxidation by epicatechin, trans-resveratrol, and gallic and caffeic acids in intestinal model systems. J Agric Food Chem 54, 10288-10293.

30. Riedl KM \& Hagerman E (2001) Tannin-protein complexes as radical scavengers and radical skins. J Agric Food Chem 49, 4917-4923.

31. Arts MJTJ, Haenen GRMM, Wilms LC, et al. (2002) Interactions between flavonoids and proteins: effect on the total antioxidant capacity. J Agric Food Chem 50, 1184-1187.

32. Roux DG (1992) Reflections on the chemistry and affinities of the major commercial condensed tannins in the context of their industrial use. In Plant Polyphenols: Synthesis, Properties, Significance, pp. 7-39 [RW Hemingway and IPE Laks, editors]. New York: Plenum.

33. Mueller-Harvey I (2006) Review: unravelling the conundrum of tannins in animal nutrition and health. J Sci Food Agric 86, 2010-2037.

34. Mueller-Harvey I (1999) Tannins: their nature and biological significance. In Secondary Plant Products: Antinutritional and Beneficial Actions in Animal Feeding, pp. 17-39 [JC Caygill and I Mueller-Harvey, editors]. Nottingham: Nottingham University Press.

35. Gladine C, Rock E, Morand C, et al. (2007) Bioavailability and antioxidant capacity of plant extracts rich in polyphenols, given as a single acute dose, in sheep made highly susceptible to lipoperoxidation. Br J Nutr 98, 691-701.

36. Moñino I, Martínez C, Sotomayor JA, et al. (2008) Polyphenolic transmission to Segureño lamb meat from ewes' diet supplemented with the distillate from rosemary (Rosmarinus officinalis) leaves. J Agric Food Chem 56, 3363-3367.

37. Porter LJ, Hrstich LN \& Chan B (1986) The conversion of procyanidins and rodelphinidins to cyanidin and delphinidin. Phytochemistry 25, 223-230.

38. Bhat TK, Singh B \& Sharma OP (1998) Microbial degradation of tannins - a current perspective. Biodegradation 9. $343-357$

39. Vasta V \& Luciano G (2011) The effects of dietary consumption of plant secondary compounds on small ruminants' products quality. Small Rum Res 101, 150-159.

40. Halliwell B, Rafter J \& Jenner A (2005) Health promotion by flavonoids, tocopherols, tocotrienols, and other phenols: direct or indirect effects? Antioxidant or not? Am J Clin Nutr 81, 268-276.

41. Kresty LA, Howell AB \& Maureen B (2011) Cranberry proanthocyanidins mediate growth arrest of lung cancer cells through modulation of gene expression and rapid induction of apoptosis. Molecules 16, 2375-2390.

42. Sgorlon S, Stradaioli G, Zanin D, et al. (2006) Biochemical and molecular responses to antioxidant supplementation in sheep. Small Rum Res 74, 17-33.

43. Larrosa M, García-Conesa MT, Espín JC, et al. (2010) Review: ellagitannins, ellagic acid and vascular health. Mol Aspects Med 31, 513-539. 